\title{
Early autonomic dysreflexia
}

\author{
JR Silver ${ }^{*, 1}$ \\ ${ }^{1}$ The Chiltern Hospital, Great Missenden, Bucks, UK
}

\begin{abstract}
Introduction: During the stage of spinal shock the conventional view is that autonomic activity is abolished. Here, evidence is presented that autonomic activity is still present.

Patients: Four patients with acute cord transactions are presented: one new case and three from the literature.

Definitions: The definitions of spinal shock and autonomic dysreflexia are given.

Methods: All four cases showed acute autonomic dysreflexia between 7 and 31 days after acute cord transection at a stage when the tendon reflexes were abolished.

Results: Two cases showed a severe rise in blood pressure; the two earlier cases, before blood pressure was routinely recorded, profuse sweating. In two cases autonomic dysreflexia was obtained when the bladder was overdistended with $1000 \mathrm{ml}$ and $1600 \mathrm{ml}$. In the other two cases it occurred in response to traumatic catheterisation. This was found when supramaximal stimuli were applied. It has not been recorded routinely as, with modern management, the bladder does not get overdistended or traumatised.

Discussion: Other evidence, the blood pressure, and urethral tone is presented to show that sympathetic reflex activity of the cord is not abolished during spinal shock.

Clinical significance: The clinical importance of this is that autonomic dysreflexia can be seen at an early stage and it should be considered in the differential diagnosis of a sick patient immediately after spinal injury.
\end{abstract}

Spinal Cord (2000) 38, 229-233

Keywords: spinal injury; spinal shock; autonomic dysreflexia; bladder stimuli

\section{Introduction}

A complete transection of the cervical cord above the sympathetic outflow interrupts all nervous pathways between the brain and spinal cord. Motor, sensory conduction and tendon reflexes are abolished. The impairment of autonomic function is a subject of debate. The atony of bowel and bladder indicates that this too is paralysed. Martin et $a l^{1}$ and Meyer et $a l^{2}$ postulated, however, on the basis of preserved anal reflex and the maintenance of blood pressure, that some reflex function is preserved.

In $1971,{ }^{3}$ a cervical patient who had an acute cord transection and who 7 days later inadvertently retained $1600 \mathrm{ml}$ of urine in his bladder, showed autonomic dysreflexia, indicating that autonomic activity was present. This was confirmed subsequently by studies in 15 tetraplegic patients in the stage of spinal shock. Mathias et $a l^{4}$ looked at the problem again in 1979 in patients in spinal shock and concluded that autonomic activity was feeble or absent.

Since the original observations in $1971,{ }^{3}$ one other patient who showed early autonomic dysreflexia has

*Correspondence: JR Silver, Consultant in Spinal Injuries, The Chiltern Hospital, Great Missenden, Bucks, UK been observed. Two further cases have been identified in the literature. ${ }^{5}$ These four cases would indicate that there is reflex autonomic activity at a spinal level in the stage of spinal shock.

\section{Definitions}

Spinal shock is the abolition of reflex activity after a complete or incomplete spinal cord transection. ${ }^{6-8}$ Tendon reflexes are most commonly affected, the anal reflex least commonly. Plantar responses may be downward going initially, later becoming extensor. Return of reflexes is gradual and in an altered form, which is one of the most intriguing features of spinal shock.

Autonomic dysreflexia is seen in high spinal cord lesions, normally above the T5 level. Stimuli originate below the level of the lesion from the skin, abdominal or pelvic viscera, skeletal muscles or, most commonly, distension of the bladder. The accepted criterion of autonomic dysreflexia is an increase in systolic blood pressure by at least $20 \%,{ }^{9}$ sometimes combined with bradycardia and occasional cardiac dysrhythmias. This may be accompanied by one or more of the following symptoms: sweating in areas above and around the lesion depending on the level of the lesion, muscle 
spasm, paraesthesiae in the neck and shoulders, headache, a feeling of fullness in the head, pallor followed by flushing of the face. Elevation of blood pressure and symptoms decline after removal of the stimulus. ${ }^{9}$

\section{Case histories}

Patient 1 (1971 original case, Table 1) sustained a complete transverse spinal cord lesion below C6 on 2.5.70 as the result of a motor cycle accident. Seven days after injury, tendon reflexes were absent, but anal reflex was present. He was being treated with intermittent catheterisation. At $06.00 \mathrm{~h}$ on $9.5 .70 \mathrm{his}$ bladder was drained. However, at $10.00 \mathrm{~h}$ he complained of severe breathlessness. He was distressed but not cyanosed. His apex beat was extremely forceful, but he made no complaint of headache. His respiration rate was 26 breaths per minute, he had scattered rhonchi, his blood pressure was $200 / 90$, heart rate 85 , and chest X-ray was normal. His blood pressure rose to $210 / 100$, his bladder was palpable and pulse 90. A catheter was passed and $1600 \mathrm{ml}$ of urine was drained. There was a dramatic change in his breathlessness, the respiration rate dropped almost immediately to 30 and the blood pressure to $180 / 70$, the heart rate dropped to 70 . Over the next $2 \mathrm{~h}$ his condition improved, the systolic pressure being the last to fall (Figure 1).

Six days later an experiment was carried out under controlled conditions and a cystometrogram was performed. The bladder was filled to $350 \mathrm{ml}$. This only produced a small rise in blood pressure from $100 /$ 50 to $120 / 60$ and no change in respiration.

Patient 2 sustained a complete transverse spinal cord lesion below C6 on 19.8.81 as a result of a road traffic accident. He was admitted the day after the accident. His tendon reflexes were present in the upper limbs and absent in the lower limbs. Anal reflex was absent. Blood pressure was 110/70. A suprapubic catheter was inserted on 29.8.81. Eleven days after injury, the suprapubic catheter was found to be blocked. His blood pressure was $150 / 90$ and pulse 72. He had $1000 \mathrm{ml}$ of urine in his bladder. He had a throbbing headache all round his head which lasted for $7.5 \mathrm{~h}$. He was catheterised and his blood pressure fell to $125 / 75$, pulse 78 . The headache regressed very slowly and his blood pressure gradually dropped. Neurological examination showed knee jerks, plantars and anal reflex to be absent. Ankle jerks were present. His condition improved but he remained with gradually diminishing headaches for some days.

Subsequently, on 3.8.83 when electrostimulation was carried out to obtain semen, he had a severe attack of autonomic dysreflexia, his blood pressure rose to $170 / 110$

Patient 3 (Head and Riddoch, ${ }^{5}$ their case 1) was wounded by a shrapnel bullet in the spine on 6th August 1916, resulting in complete flaccid paralysis below T6. On admission 10 days after injury there was retention of urine, requiring catheterisation every $6 \mathrm{~h}$. Sweating was absent over the trunk and lower extremities. Twenty-two days after injury, knee and ankle jerks were negative, plantars were upgoing and anal reflex tonic but he was getting bouts of sweating on the left side of the head and neck, left arm, and down to the level of the third interspace. The skin of the right arm, right half of the face, and all the trunk below the level of the fifth rib was dry. He had a laminectomy 33 days after injury. When the catheter was passed along the urethra considerable resistance was offered to its passage as the tip impinged against the sphincter. These manipulations produced a profuse

Table 1 Summary of clinical findings

\begin{tabular}{|c|c|c|c|c|c|c|}
\hline Case & Level of injury & Time of onset & Provoking stimulus & & $\begin{array}{c}\text { Reflexes } \\
R\end{array}$ & $L$ \\
\hline $\begin{array}{l}\text { Case } 1 \\
\text { Original } \\
\text { case } 1971\end{array}$ & C6 complete & 7 days & $\begin{array}{l}\text { Bladder distension } \\
1600 \mathrm{ml}\end{array}$ & $\begin{array}{l}\text { Knee jerks } \\
\text { Ankle jerks } \\
\text { Anal reflex } \\
\text { Plantars }\end{array}$ & $\begin{array}{l}- \\
- \\
+ \\
-\end{array}$ & $\begin{array}{l}- \\
- \\
-\end{array}$ \\
\hline Case 2 & C6 complete & 11 days & $\begin{array}{l}\text { Bladder distension } \\
1000 \mathrm{ml}\end{array}$ & $\begin{array}{l}\text { Knee jerks } \\
\text { Ankle jerks } \\
\text { Anal reflex } \\
\text { Plantars }\end{array}$ & $\begin{array}{l}- \\
+ \\
- \\
-\end{array}$ & $\begin{array}{l}- \\
+ \\
-\end{array}$ \\
\hline $\begin{array}{l}\text { Case } 3 \\
\text { Head and } \\
\text { Riddoch case }\end{array}$ & D6 complete & 22 days & Catheterisation & $\begin{array}{l}\text { Knee jerks } \\
\text { Ankle jerks } \\
\text { Anal reflex } \\
\text { Plantars }\end{array}$ & $\begin{array}{c}- \\
- \\
\text { tonic } \\
\text { upgoing }\end{array}$ & $\begin{array}{c}- \\
- \\
\text { upgoing }\end{array}$ \\
\hline $\begin{array}{l}\text { Case } 4 \\
\text { Head and } \\
\text { Riddoch case }\end{array}$ & C5 incomplete & 31 days & Catheterisation & $\begin{array}{l}\text { Knee jerks } \\
\text { Ankle jerks } \\
\text { Anal reflex } \\
\text { Plantars }\end{array}$ & $\begin{array}{c}- \\
- \\
\text { not recorded } \\
\text { absent }\end{array}$ & $\begin{array}{c}- \\
- \\
\text { extensor }\end{array}$ \\
\hline
\end{tabular}


outburst of sweating of the trunk and limbs below the level of the 4th rib. When the stimulus was discontinued the sweating disappeared. The use of an enema also induced sweating. Fifty-two days after the injury there was a gradual return of reflex activity. By 87 days both knee jerks and ankle jerks were increased.

Patient 4 (Head and Riddoch, ${ }^{5}$ their case 8) was injured on 24th August 1916 by a high explosive shell. On admission 31 days after injury he had an incomplete lesion at C5. Knee jerks and ankle jerks were absent, plantar response was absent on the right, extensor on the left. Anal reflex was not recorded. The bladder acted involuntarily and automatically but the patient could recognise the passage of urine and knew when fluid was being injected into his bladder. Episodes of intense sweating occurred in association with blockage of the catheter or administration of an enema. Sweating occurred over the right half of the head and neck and was frequently associated with slowing of the pulse.

\section{Discussion}

All four patients, examined between 7 and 31 days, were considered to be in spinal shock. The tendon reflexes were absent in all four, the plantar responses were absent in one and the anal reflex was absent in one of the three patients in whom it was recorded. All the patients fulfilled the diagnostic criteria for autonomic dysreflexia. Patients 1 and 2 exhibited elevation of blood pressure of more than $20 \%$ accompanied in patient 2 by headache. Patients 3 and 4 were managed at a time when blood pressure was not routinely recorded. However they showed profuse sweating in areas adjacent to the level of cord transection, that disappeared on removal of the stimulus. In patient 4 , slowing of the pulse was also noted.

The stimulus was distension of the bladder in patients 1, 2 and 4, associated with obstruction of the catheter in the latter two. In patient 3 the stimulus was the traumatic insertion of a catheter. Administration of an enema was also observed to cause sweating in patients 3 and 4 . Autonomic dysreflexia is considered to occur when, in response to an appropriate stimulus, there is an increase in systolic blood pressure by at least $20 \%$ combined with at least one of the following symptoms: sweating, chills, cutis anserine, headache or flushing. ${ }^{9}$ Abnormal sweating is regarded as an outstanding component in symptomatology and, in the absence of blood pressure records as

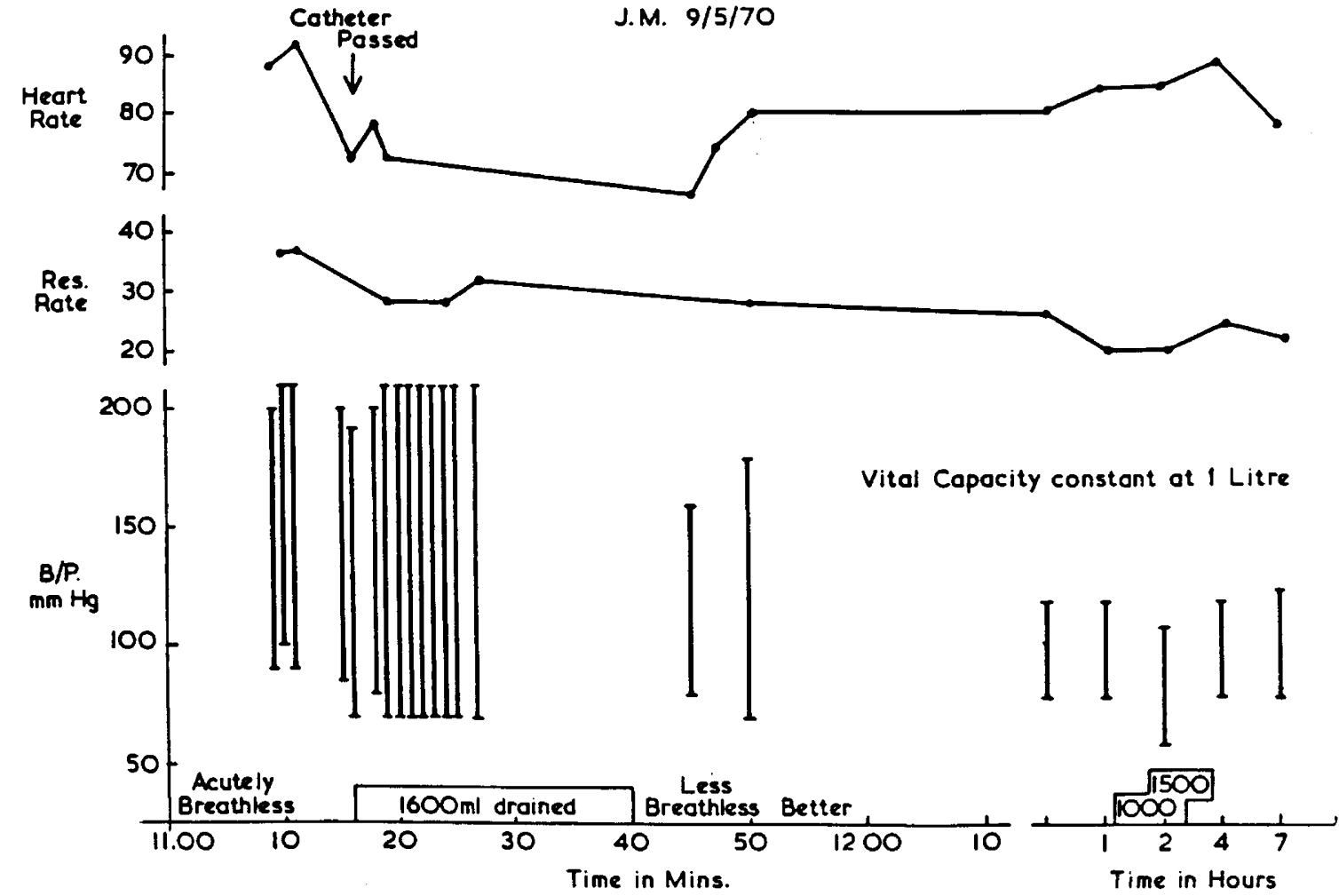

Figure 1 Case 1 sustained a complete transverse spinal cord lesion below the sixth cervical segment on 2 May. He was being treated by intermittent catheterisation. At $06.00 \mathrm{~h}$ on 9 May his bladder was drained. However, by $10.00 \mathrm{~h}$ he was very breathless but had no headache. His respiratory rate was 36 breaths per minute, blood pressure $200 / 90 \mathrm{mmHg}$. Drainage of $1600 \mathrm{ml}$ of urine from his bladder relieved all his symptoms. An example of autonomic dysreflexia occurring 1 week after injury. (Reprinted by kind permission of Update Publications Limited) 
in patients 3 and 4, is strongly indicative of the occurrence of autonomic dysreflexia. ${ }^{10}$ It usually occurs in patients with complete lesions above T6, but has been described both in patients with lesions between $\mathrm{T} 5$ and $\mathrm{T} 10$ as well as in patients with incomplete cord lesions. ${ }^{10}$ This would include patient 3 (T6 complete) and patient 4 (C5 incomplete).

Spinal shock is generally considered to occur only in cases of complete cord lesion. However, again, spinal shock has been described in patients with incomplete lesions. ${ }^{5}$ In patients with lesions above T6, Lindan ${ }^{11}$ found no cases of autonomic dysreflexia in the first month, while Kewalramani ${ }^{12}$ recorded the earliest cases 4 weeks after injury. These findings of autonomic activity presented here in the stage of spinal shock are not unique. Other investigators have also found autonomic activity.

Martin et $a l^{1}$ and Meyer et $a l^{2}$ have found normal blood pressure and in the study in $1971^{3}$ normal blood pressure is reported. Further studies (Table 2 unpublished work) show figures in complete cervical patients of $119 / 71$, in incomplete cervical patients of $114 / 65$, and slightly lower in thoracic and lumbar patients at 124/71. These findings are similar to those of Mathias et $a l^{4}$ who record blood pressures of $130 /$ 57 in recently injured tetraplegics and 107/55 in chronic tetraplegics. They quoted observations by Walsh $^{13}$ that hypertension can occur in recently injured tetraplegics during blood or saline infusion.

Rossier ${ }^{14}$ made detailed studies on autonomic function in the stage of spinal shock in 17 patients. He found that bladder filling was accompanied by elevation of resistance in the bladder neck due to increased sympathetic activity in the smooth muscle component of the entire urethra. This pressure decreased after the administration of an alphaadrenergic blocking agent in two patients. This was at a time when the striped muscle component was in abeyance.

In the present report the study on patient 1 was repeated by carrying out a cystometrogram but only filling the bladder to $350 \mathrm{ml}$. Systolic blood pressure increased by $20 \%$ but no symptoms were precipitated. Further cystometrograms on three other patients in spinal shock ${ }^{3}$ showed small increases in pressure but it clearly would have been unethical to carry out the cystometrograms beyond the stage of $350 \mathrm{ml}$ filling. Mathias et $a l^{4}$ carried out similar investigations on patients in spinal shock. They relied on the bladder being distended by natural filling and the stimulus was percussion of the bladder. The mean change in blood pressure was from $130 / 58$ to $138 / 60$.

This evidence suggests that there is a reduction rather than an abolition of spinal autonomic activity in the state of spinal shock. As the shock subsides, other reflexes apart from the tendon reflexes, return. It is at this stage that autonomic dysreflexia usually manifests itself. Why is this activity seen in these four patients when not recorded either clinically or by other investigators?

In the stage of spinal shock, the autonomic activation of the bladder by the parasympathetic nerves is abolished. The bladder is atonic (Holmes, ${ }^{15}$ Munro, ${ }^{16}$ Rossier $^{14}$ ) and can fill to a much larger capacity than normal without any detrusor contractions occurring. Destruction of the pontine micturition centre or interruption of the neuraxis below the pons by spinal cord transection causes the immediate elimination of the micturition reflex and the slow development of involuntary, uncoordinated, spinal mechanisms which mediate automatic voiding in paraplegic patients and animals. ${ }^{17}$

The sympathetic innervation of the bladder is not considered of prime importance in the motor side of voiding. However there are sympathetic receptors at the bladder neck whose distribution is significant and serve as the receptors for autonomic dysreflexia from bladder filling. The act of normal micturition is initiated by cortical control. The brain receives afferent signals from the bladder and urethra through the posterior columns, spinothalamic and spinocerebellar tracts and descending motor pathways travelling in the corticospinal and reticulospinal tracts.

In all the patients described here, the stimulus was clearly supramaximal and was not produced as an experimental situation. The effects were seen in patients when the catheter had blocked or was extruded and led to the gradual distension of the bladder so that unphysiological quantities of urine were retained, $1000-1600 \mathrm{ml}$ and even though the bladder was atonic eventually the receptors at the bladder neck were stimulated. The two cases described

Table 2 Blood pressure readings and serum sodium in 33 acute spinal injuries from Silver, Burr \& Doggart - unpublished work. Plasma sodium levels and systolic and diastolic blood pressure in patients who did not receive $\mathrm{NaCl}$ supplements

\begin{tabular}{lrrrrrrrrrr}
\hline & \multicolumn{4}{c}{} & \multicolumn{4}{c}{ Plasma sodium } & \multicolumn{3}{c}{ Blood pressure (mmHg) } \\
& $n$ & Range & Mean & s.d. & Range & Mean & s.d. & Range & Mean & S.d. \\
\hline Complete cervical patients & 7 & $128-137$ & 134.0 & 3.46 & $101-137$ & 119 & 11.5 & $61-79$ & 71 & 6.0 \\
Incomplete cervical patients & 6 & $134-145$ & 139.2 & $4.15^{*}$ & $104-120$ & 114 & 6.2 & $52-72$ & 65 & 6.7 \\
Thoracic and lumbar patients & 9 & $137-145$ & 139.8 & $2.66^{* *}$ & $120-126$ & 124 & 2.6 & $60-80$ & 71 & 6.0 \\
+ Associated injuries & 11 & $134-144$ & 138.3 & $3.40^{* * *}$ & $106-146$ & 124 & 10.0 & $58-85$ & 73 & 6.9 \\
\hline
\end{tabular}

*Different from complete cervicals: $P=0.0007$; **Different from complete cervicals: $P=0.00008$; ***Different from thoracic and lumbar lesions: $P=0.0049$ 
by Head and Riddoch ${ }^{5}$ occurred when the bladder activity was heightened because of the trauma to the urethra by traumatic catheterisation. Sommer and Roberts ${ }^{18}$ have shown that the force of contraction in the bladder is increased by infection so that the afferent receptors were stimulated by infection and trauma. At a later stage both the bladder capacity becomes smaller and detrusor contractions occur. Detrusor contractions are a potent stimulus for autonomic dysreflexia. No doubt the contraction of the bladder and the pulling open of the bladder neck causes stimulation of the receptors at the bladder neck which initiate autonomic dysreflexia.

A distinction must be made between physiological filling of the bladder by urine which is slow and a speedy infusion when the bladder is filled during a cystometrogram. These will produce different effects. The slow filling takes much longer to elucidate reflex contractions whereas the rapid filling during a cystometrogram produces reflex contractions at a much smaller volume. The physiological implications are that the pathway can be activated by a supramaximal stimulus as shown when stimulating tendon reflexes but that it is inactive to normal stimuli.

This is borne out by Riddoch's work who, in $1917,{ }^{19}$ studied patients in spinal shock and showed that tendon reflexes could be produced by increasing the force of stimuli. The clinical implications are that autonomic dysreflexia can occur in spinal shock. In a breathless and distressed patient in the stage of spinal shock the possibility that autonomic dysreflexia is present should be considered. The blood pressure should be measured, the bladder drainage checked and other sources such as a fissure in ano or ingrowing toenails should be considered.

\section{References}

1 Martin J, Davis L. Studies upon spinal cord injuries. III. Altered reflex activity. Surg Gynec Obstet 1948; 86: 535-542.
2 Meyer GA et al. Hemodynamic responses to acute quadriplegia with or without chest trauma. J Neurosurg 1971; 34: $168-177$.

3 Silver JR. Vascular reflexes in spinal shock. Paraplegia 1971; 8: $231-242$.

4 Mathias CJ, Christensen NJ, Frankel HL, Spalding JMK. Cardiovascular control in recently injured tetraplegics in spinal shock. Quart J Med 1979; 190: 273 - 287.

5 Head $\mathrm{H}$, Riddoch $\mathrm{G}$. The autonomic bladder, excessive sweating and some other reflex conditions in gross injuries of the spinal cord. Brain 1917; 40: $188-263$.

6 Hall M. Synopsis of the Diastaltic Nervous System. 2nd edn. Joseph Mallett: London 1850.

7 Sherrington CS. The integrative action of the nervous system. Constable: London 1910.

8 Wall PD. Mechanisms of plasticity of connections following damage in adult mammalian nervous systems. In: Bach-y-Rita P. (ed): Recovery of function theoretical considerations for brain injury rehabilitation. University Park Press: Baltimore, Maryland, 1980, pp 91-105.

9 Karlsson AK. Autonomic dysreflexia. Spinal Cord 1999; 37: $383-391$

10 Guttmann L, Whitteridge D. Effects of bladder distension on autonomic mechanisms after spinal cord injuries. Brain 1947; 70: $361-404$

11 Lindan R, Joiner E, Freehafer AA, Hazel C. Incidence and clinical features of autonomic dysreflexia in patients with spinal cord injury. Paraplegia 1980; 18: 285-292.

12 Kewalramani LS. Autonomic dysreflexia in traumatic myelopathy. Am J Phys Med 1980; 59: 1-21.

13 Walsh JJ. Cardiovascular complications in paraplegia. Proceedings of Scientific Meeting, International Stoke Mandeville Games, Rome. 1960; 37-45.

14 Rossier AB, Fam BA, Dibenedetto M, Sarkarati M. Urodynamics in spinal shock patients. J Urol 1979; 122: $783-787$.

15 Holmes G. Observations on the Paralysed Bladder. Brain 1933; 56: $383-396$

16 Munro D. The treatment of injuries to the nervous system. Saunders: Philadelphia 1952.

17 de Groat WC. Neural control of the urinary bladder and sexual organs. In: Bannister R \& Mathias CJ (ed). Autonomic Failure. 3rd edn. Oxford Medical Publications: New York 1992, pp 129 159.

18 Sommer JL, Roberts JA. Ureteral reflux resulting from chronic urinary infection in dogs: long term studies. J Urol 1966; 95: $502-510$

19 Riddoch $\mathrm{G}$. The reflex functions of the completely divided spinal cord in man, compared with those associated with less severe lesion. Brain 1917; 40: $264-402$. 